Research Article

\title{
Optimization of Stope Structure Parameters Based on the Mined Orebody at the Meishan Iron Mine
}

\author{
Mingzhi Sun $(\mathbb{D}$, Fengyu Ren $(\mathbb{D}$, and Hangxing Ding $(\mathbb{1})$ \\ School of Resources and Civil Engineering, Northeastern University, Shenyang 110819, China \\ Correspondence should be addressed to Hangxing Ding; dinghangxing@mail.neu.edu.cn
}

Received 2 June 2021; Accepted 17 June 2021; Published 9 July 2021

Academic Editor: Gan Feng

Copyright (C) 2021 Mingzhi Sun et al. This is an open access article distributed under the Creative Commons Attribution License, which permits unrestricted use, distribution, and reproduction in any medium, provided the original work is properly cited.

Based on the engineering background of the Meishan iron mine with sublevel caving (SLC) method, in this work, we adopted the method for identifying the shape of mined orebody (the original location in blasted slice), which analyzed and determined reasonable stope structure parameters. In the field test, the markers were arranged in the blasted slice, the mined orebody was measured by in situ tests, and reliable data were achieved. The shape of the mined orebody was obtained through this test when the width of drift was $6 \mathrm{~m}$. The mined orebody's shape was compared with the shape of the isolated extraction zone (IEZ), and the difference increased with increasing height. When the stope structural parameters were determined by the mined orebody, the larger the sublevel height was, the smaller the error was, which was compared with the method using ellipsoid arrangement theory to determine the stope structural parameters. Finally, the reasonable stope structure parameters were optimized. The sublevel height was $22 \mathrm{~m}$, and the drift spacing was $20 \mathrm{~m}$.

\section{Introduction}

The characteristic of the SLC method is the large contact area between blasted ores and the caved waste from the overlying rock mass. The overall shape of the blasted ores and the residual ores is less consistent with the IEZ's shape if the stope structure parameters mismatch the flow behavior of blasted ores [1-6]. A great deal of waste rock was prone to mix with the ores in the drawing process, which could result in low ore recovery and high dilution.

The key to effectively reduce the ore loss and dilution rate in the SLC method was the reasonable stope structure parameters. The researchers had proposed various optimization methods for stope structure parameters based on IEZ's shape [7-15]. Kvapil et al. [16] conducted many research works on the design and optimization of structural parameters in the SLC method. The result shown that the shape of blasted ores and IEZ followed the consistency principle, which based on the ellipsoid draw theory. According to the empirical formula of our design, blasted ores, and the properties of caved rock as the guidance, an ellipsoid was extracted with certain width and thickness [17-23]. Castro et al. [24-29] proposed a mining theory of high sublevel and large drift spacing based on the ore drawing theory, adjusted the sublevel height and drift spacing in different mines accordingly, and implemented it. In addition, extensive literature indicated that the decreased ore loss and dilution rate depended on the reasonable stope structure parameters [30-36]. Tan et al. [37] proved that the optimization of stope structural parameters based on ellipsoid arrangement theory was not rigorous and perfect, which did not follow the consistent principle of the blasted ores and IEZ's shape in essence. Further, our research group had obtained the IEZ's shape of the Meishan iron mine in the previous particle flow experiments. The IEZ's shape was arranged by ellipsoid arrangement theory, and the optimized stope structural parameters were obtained. However, the loss and dilution index of ores was unsatisfactory in practical applications. The main reasons are as follows: (1) when the structural parameters of stope before blasting were optimized by the IEZ's shape after blasting, the shape change of ore-rock body was ignored during the blasting process; (2) the structural parameters determined based on the IEZ's shape 
deviated from the optimal value, due to the lack of understanding of drawn ores' shape within burden spacing before blasting.

Here, based on the above deficiencies, a new method to determine the shape of the mined orebody by the in situ test was proposed. According to the ellipsoid arrangement theory, the stope structure parameters were optimized by the mined orebody's shape measured in the field test. Therefore, there was a direct correlation between the mined orebody's shape and the structural parameters, but the indirect relationship existed between IEZ's shape and the stope structure. It could avoid the change of the ore-rock body's form during the blasting process. This method has a significant meaning to further reduce the loss and dilution rate of the SLC method and ensure the full use of metal mineral resources.

\section{In Situ Mined Orebody Measurement Test}

2.1. Meishan Iron Mine SLC Operation. The Meishan SLC iron mine was located at Yuhuatai District, Nanjing city of China, which was one of the first batches of technologically advanced mines to adopt the SLC method in China, and the ore loss and dilution control technology was advanced. Recently, the tests of large drift spacing structural parameters were conducted which are based on the original structural parameter $(15 \mathrm{~m} \times 15 \mathrm{~m})$. The test results were not satisfactory; the ore loss and dilution rate were not significantly reduced under the condition that the sublevel height is $15 \mathrm{~m}$ and the drift spacing is $20 \mathrm{~m}$. Particularly, the new structural parameter $(18 \mathrm{~m} \times 20 \mathrm{~m})$ was adopted in the second stage of the extension of the operation, but the ore loss rate and dilution rate also have not been significantly reduced. Therefore, in situ tests on the mined ore body's shape were employed to optimize the structural parameters of the mining of deep ore body and further reduce the ore loss and dilution rate.

The mined orebody's shape was essential to the determination of stope structural parameters. The shape and size of a single blasted slice and the shape of the blasted ores were determined by the stope structure parameters. The IEZ's shape was consistent with that of the blasted ores and residual ores, which indicated that the mined orebody's shape coincided with the blasted slice and the stope structural parameters were reasonable.

A single blasted slice in drawing drift by the SLC method is shown in Figure 1(a). The holes were drilled in fan rings before blasting for placing the markers and arranged in the middle of the two rows of blast holes. The ores contained markers that would be blasted and drawn. The IEZ's shape came from experiments, as shown in Figure 1(b). According to the drawing theory, the shape of mined orebody was depicted by the method of determining the IEZ's shape [8]. The corresponding quality of drawn ores was measured when the blasted ores containing markers were drawn, and the mined orebody's shape could be obtained. This method was called in situ mined orebody measurement test. The mined orebody was a solid ore block with a particular shape rather than ores. The ideal stope structural parameters could make the blasted ores completely contained by the IEZ, and a directionless drawing was achieved before the stage of recovery of upper residual ores. Meanwhile, in an ideal situation, the whole of ores that came from the blasted slice should be completely drawn, but it is difficult to achieve in real production. In practice, part of the blasted ores could not be drawn, which led to an obvious difference between the mined orebody and the original blasted slice. The schematic diagram of mined orebody is shown in Figure 1(c).

2.2. Experimental Setup. To determine the mined orebody's shape, the operation is selected in row 10 of $S 1$ drift at $-306 \mathrm{~m}$ level in the Meishan iron mine. The details of the test location and mining preparation works are shown in Figure 2. The relationship between the position of markers and blast holes is depicted in Figure 3. To determine the rationality of stope structure parameters, the bottom position of the holes should be focused on monitoring. Meanwhile, the original blasted slice must be covered to the fullest degree. The rationality of stope structure parameters could be verified by the shape of the loss dilution index, and the optimized structural parameters could be determined by the mined orebody. The markers that adopted RFID technology are shown in Figure 4(a). RFID was a flexible application technology that is easy to operate, simple and practical, and especially suitable for automatic control. The recognition work needs no manual intervention, which supported both read-only mode and read-write mode, and needs no touch or aim. RFID technology has many advantages, such as convenient and fast reading, more effective recognition distance, fast recognition speed, good penetration, long service life, wide application range, strong resistance to pollution, and durability. Meanwhile, the location of markers was important considerations in depicting the geometry of the mined orebody. Therefore, the markers should be able to actively transmit signals, resist blasting impact, and avail to monitor.

The charge trolley of the Meishan iron mine was employed for the installation of markers; the process is shown in Figure 4(b). It could precisely control the depth of the placement and ensure that the installed markers reach the designed position. The woven bags were used for fixing markers; that is, the gaps during the markers in the drilling holes were filled with woven bags and compacted. As shown in Figure 4(c), the woven bags were used as the interval between the markers, and it played a good role in fixing the interval for the markers. The markers should be stouter enough to survive from the first blasting process and subsequent ore drawing to ensure sufficient data for further analysis.

2.3. Test Process and Data. The positions of each marker are shown in Figure 5, and these markers covered the range of the blasted slice. In Figure 5, 79 markers were installed in the test ore body. Among them, 11 markers were installed in No. 1 hole, 18 markers were installed in No. 2 hole, 23 markers were installed in No. 3 hole, 16 markers were installed in No. 4 hole, and 11 markers were installed in No. 5 hole.

To monitor the markers during the drawing, the layout of each piece of equipment and data lines in the stope drift is shown in Figure 6. Two marker monitors were arranged on the roof of the drift near the drawing point of S1 and next to 


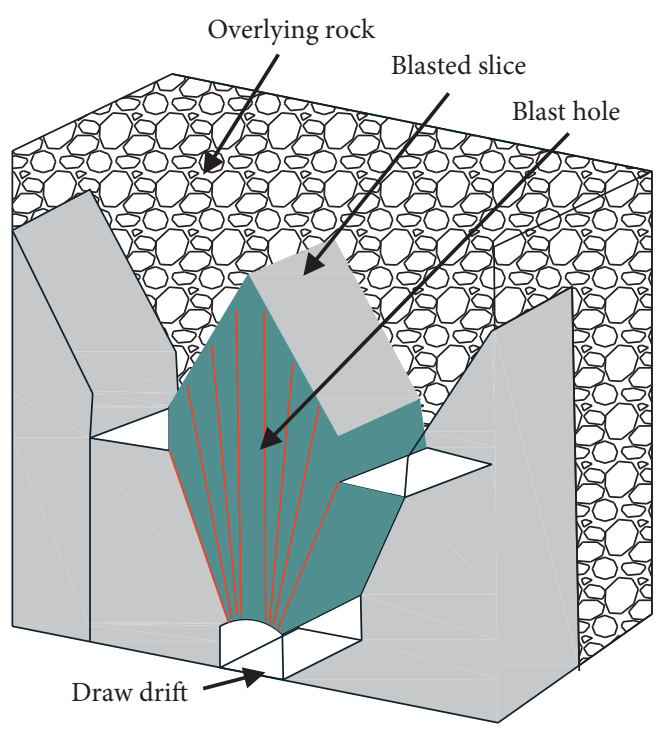

(a)

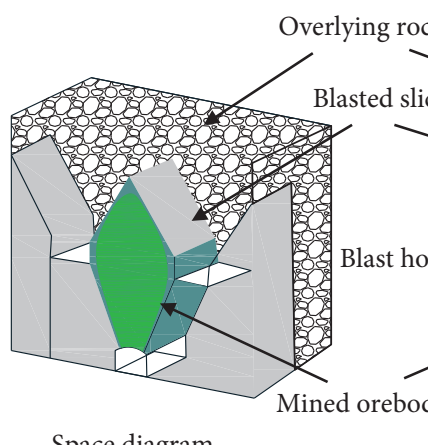

Space diagram

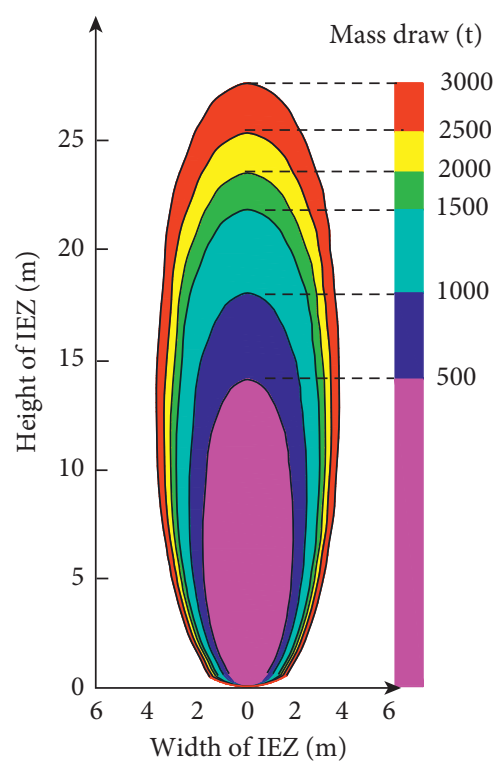

(b)

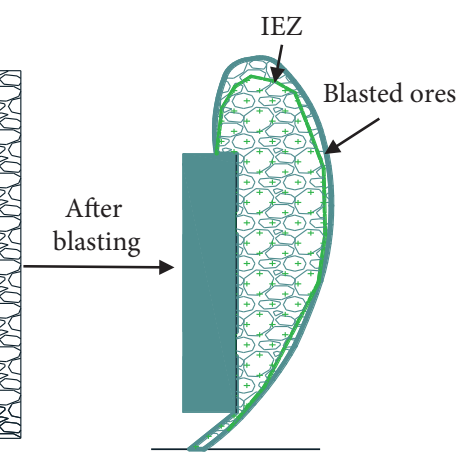

(c)

FIgure 1: (a) A single blasted slice. (b) The IEZ's shape of the end drawing in the direction of vertical drift. (c) Schematic diagram of mined orebody's shape.

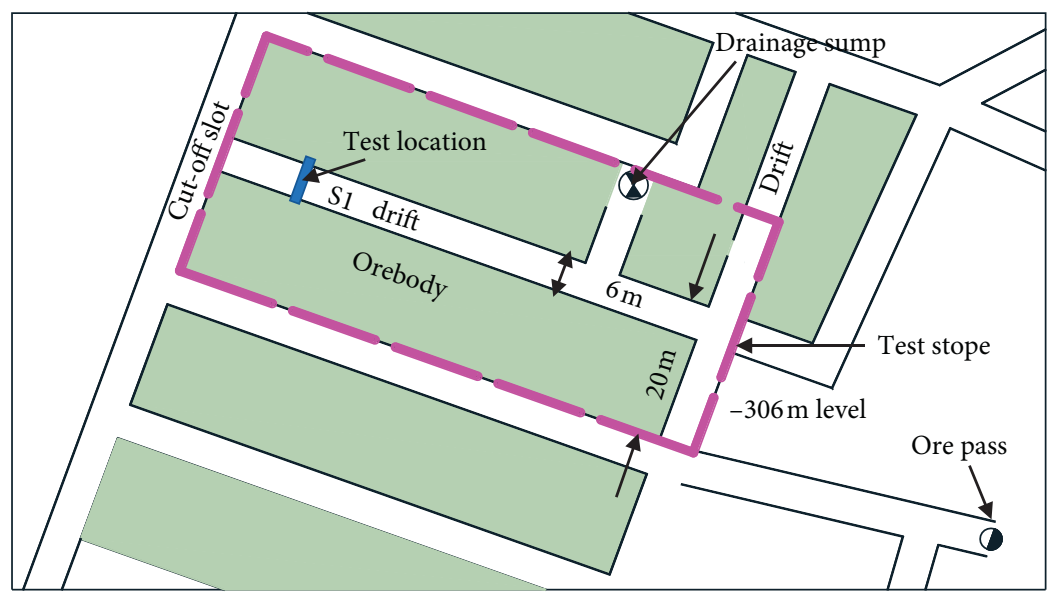

FIgURE 2: The layout of the test location and mining preparation works.

the ore pass, respectively. When the ores flowed from the drawing point, the first monitoring was completed. When the ores were transported to the ore pass by the scraper, the second monitoring was completed. Meanwhile, a monitor was arranged on the roof of the drift near the drawing point to obtain the ores flow video. The monitoring station was arranged in the S5 extension drift, and the 485 hubs and laptop were placed in it. It is used to observe the running 


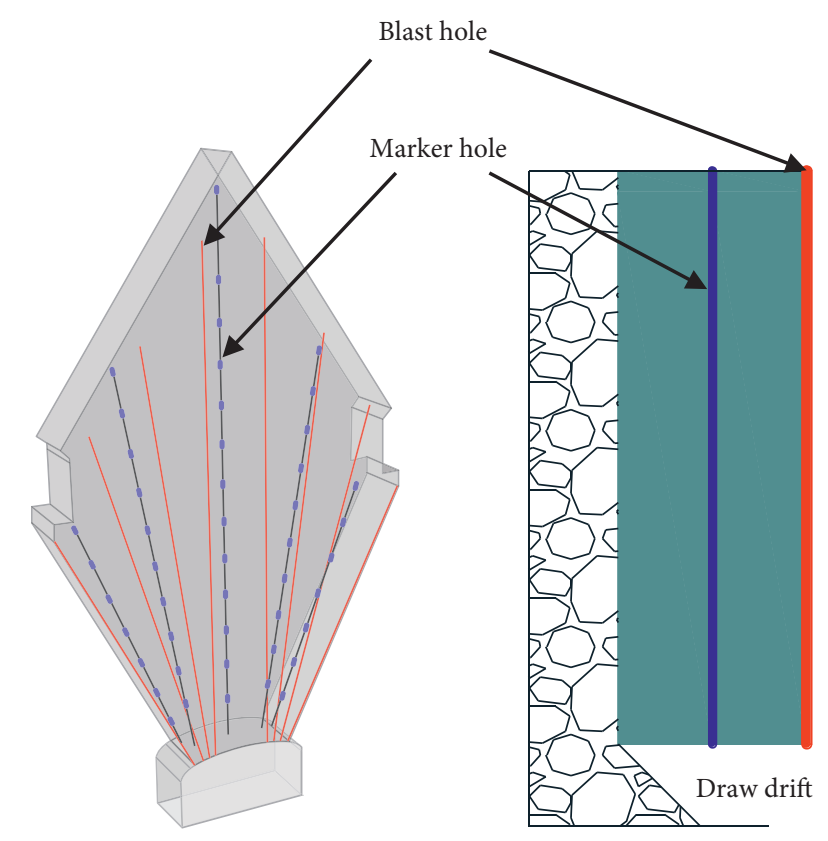

FIGURE 3: The relationship between the position of markers and blast holes.

condition of the system. The data line and power line should be fixed on the roof of the drift to avoid damaging the wire by mining equipment in operation.

The $5.6 \mathrm{~m}^{3}$ scrapers were employed in the test, with 206 scoop ores being drawn. The average scoop of ores weighed about $15 \mathrm{t}$, and the quantity of the total ore was about $3090 \mathrm{t}$. The dilution occurs at about 140 scoops, and before that, it was a nondilution drawing. A total of 54 markers were detected in the test, and the $2,14,22,11$, and 5 markers are recycled from the corresponding holes (Nos. 1-5), respectively. As shown in Figure 7, the green solid circle indicates that the markers could be monitored.

2.4. Test Result. Mined orebody in situ measurement test was accomplished by RFID technology, and better test results had been obtained. The number of markers detected in each hole in the test and overall monitoring situation is shown in Figure 8. The comprehensive monitoring rate of the markers was $68.4 \%$, which reached the expected test result. A sufficient number of markers were monitored, which provided abundant data for the determination of the mined orebody's shape.

\section{Analysis of the Test Result}

3.1. The Determined Shape of a Mined Orebody. According to the above information, the markers with the same quality of drawing ores were selected, and based on the position in the blasted slice of different markers, mined orebodies' shapes with corresponding quality of drawing ores were obtained. The markers recycled in the test and their corresponding quality of drawing ores are shown in Figure 9(a). The mined orebody's shape was depicted by the data from different qualities of drawing ores $(500,1000$,
$1500,2000,2500$, and $3000 \mathrm{t}$ ), which are displayed in Figure 9(b). The volume of mined orebody increased with the increase of drawing ores, it was not the same as the corresponding IEZ, but the overall shape was roughly the same. The nondilution drawing occurred before $2000 \mathrm{t}$, and the width and height of the mined orebody increased in this process. When the quality of drawing ores was greater than $2000 \mathrm{t}$, the waste rock would be mixed, and the width and height of the mined orebody increased slowly, which influence the development speed of mined orebody's shape. It is probably due to the dilution phenomenon that appeared when the quality of drawing ores was greater than $2000 \mathrm{t}$.

When the quality of drawing ores was $500 \mathrm{t}$, the volume was calculated as $200 \mathrm{~m}^{3}$, and the height of the IEZ was $13.1 \mathrm{~m}$. When the quality of drawing ores was 1000,1500 , 2000,2500 , and $3000 \mathrm{t}$, respectively, the corresponding heights of the IEZ were calculated as 16.9, 20, 22.2, 22.5, 24.5, and $26.4 \mathrm{~m}$. The development process of the mined orebodies and IEZs is shown in Figure 10(a)-10(f). The magenta and green lines represented the shape of the IEZ and mined orebody. The height of the mined orebodies was calculated as 11.8, 14.8, 18.5, 20.9, 22.3, and $24.9 \mathrm{~m}$, respectively.

It could be seen from the shape comparison diagram of the mined orebody and the IEZ that the height of the IEZ was greater than the height of the mined orebody, and the width of the mined orebody was larger than that of the IEZ. It is indicated that the blasting range of the ores was contained in the IEZ, which was produced through the blasting of the blasted slice. The ores on both sides of the blasted slice tended to squeeze inward during the blasting. According to Figure 10(f), when the quality of the drawing ores was $3000 \mathrm{t}$, the widths of IEZ and mined orebody were 8.28 and $11.65 \mathrm{~m}$, respectively. In a comparison of the width and height of IEZ and mined orebodies, their relationship could be expressed as $S_{m} / H_{m}=1.49 S_{d} / H_{d}\left(S_{m}\right.$ and $H_{m}$ were the height and width of mined orebody; $S_{d}$ and $H_{d}$ were the height and width of IEZ). It could be seen that the difference in proportion existed between the IEZ and mined orebody. The determination of stope structural parameters according to the IEZ's shape made a certain error.

Owing to the use of cut-off grade drawing ore, the whole drawing process included three stages, which were no dilution, dilution, and up to cut-off grade. The height and corresponding width of the mined orebody at the different quality of drawing $(500,1000,1500,2000,2500$, and $3000 \mathrm{t})$ are listed in Table 1. The above data were imported into the origin software and fitted. $Z$ was the independent variable, $Y$ was the dependent variable, and $Z$ and $Y$ represented the height and width of the mined orebody, respectively.

As shown in Figure 11, it was found that the data followed the first-order equation $(y=0.47 z+0.81)$ after fitting. $R^{2}$ was 0.96 , which was close to 1 and indicated that the fitting degree is high. In the drawing, with the increased quantity of mined ores, the development width of mined orebody was directly proportional to its height.

According to the fitting results, the mined orebody's was modified, the final shape looks like an inverted water droplet (Figure 12). 


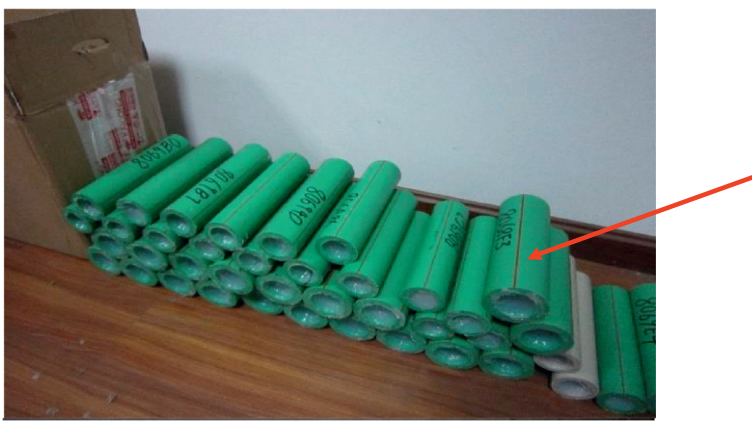

(a)

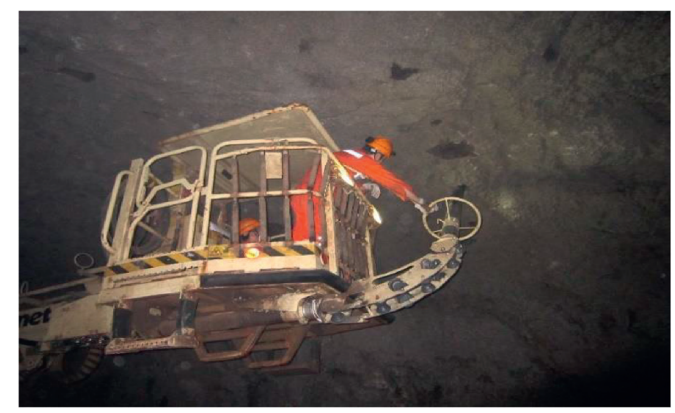

(b)

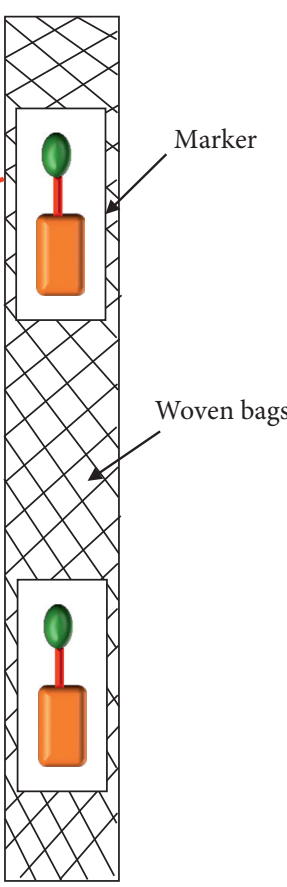

(c)

FIGURE 4: Photographs of markers and installing process: (a) markers; (b) installation markers by charge trolley; (c) profile of marker.

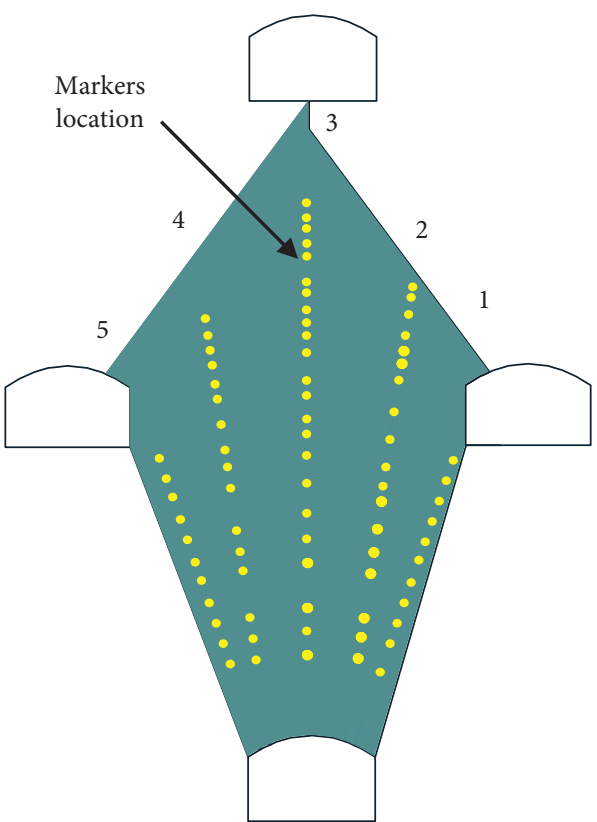

FIGURE 5: The installation structure diagram of markers and the location in fan rings.

3.2. Comparison of Stope Structure Parameters. In the past, the ellipsoid arrangement theory was used to determine the structural parameters of the SLC method. It followed the principle; that is, the shape of blasted ores was consistent with IEZ. The essence of structural parameter optimization was the space arrangement optimization of IEZ. When the 4 ellipsoids were arranged in space, the 5 points were tangent to each other, and the optimal structural parameters could be obtained. The results of practical application in mine were unsatisfied when the stope structural parameters were determined by IEZ's shape. It is difficult to achieve the ideal index of the ore recovery effect. Analysis of the main reasons is as follows: the theoretical analysis and practical demonstration of this method were insufficient. The shape of the ore block was directly arranged by IEZ's shape, which lacked the necessary correlation analysis. By comparing the IEZ's shape and measured mined orebody's shape, it could be concluded that certain errors existed when the stope structure parameters were determined by ellipsoid arrangement theory.

The viewpoints of used ellipsoid arrangement determined structural parameters are as follows: (1) If the 5 points that were the tangent of IEZ in each stope units could not be achieved, it would cause the loss of ore. If the IEZ in each stope units crossed each other, it would lead to ore dilution due to repeated drawing. (2) "The optimal structural parameters for the high coincidence degree between the blasted ores and IEZ's shape" were equivalent to "the optimal structural parameters which were obtained when the IEZs without waste rock were tangent with each other." (3) According to the IEZ arrangement of 5 points that were tangent to each other for the best, two optimal ellipsoid arrangement models could be obtained. One is the high sublevel structure, and the other is the large spacing structure. According to the shape of the measured mined orebody and IEZ, the specific arrangement is displayed in Figure 13. Figure 13(a) is the large spacing arrangement. When the IEZs were tangent to each other, the overlapping parts occurred among the mined orebodies. Figure 13(b) shows the high sublevel arrangement, the 


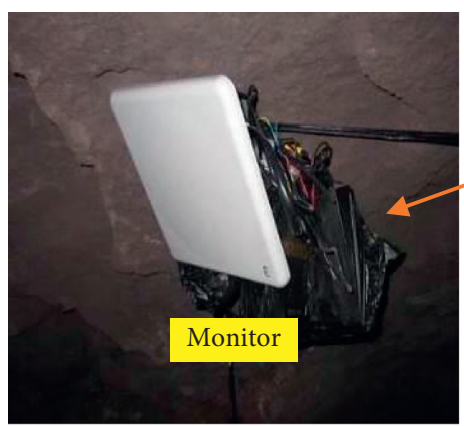

(a)

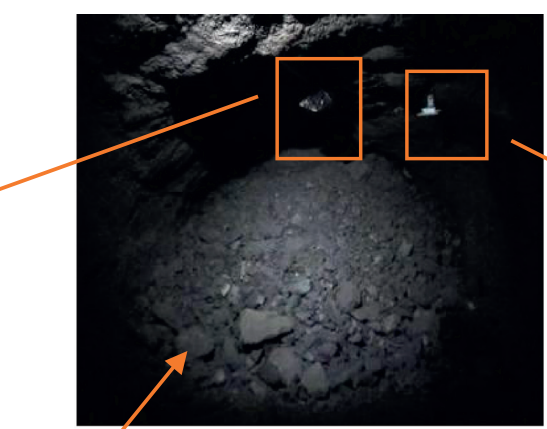

(b)

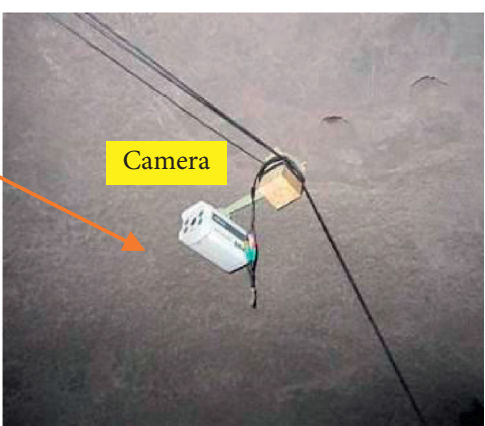

(c)

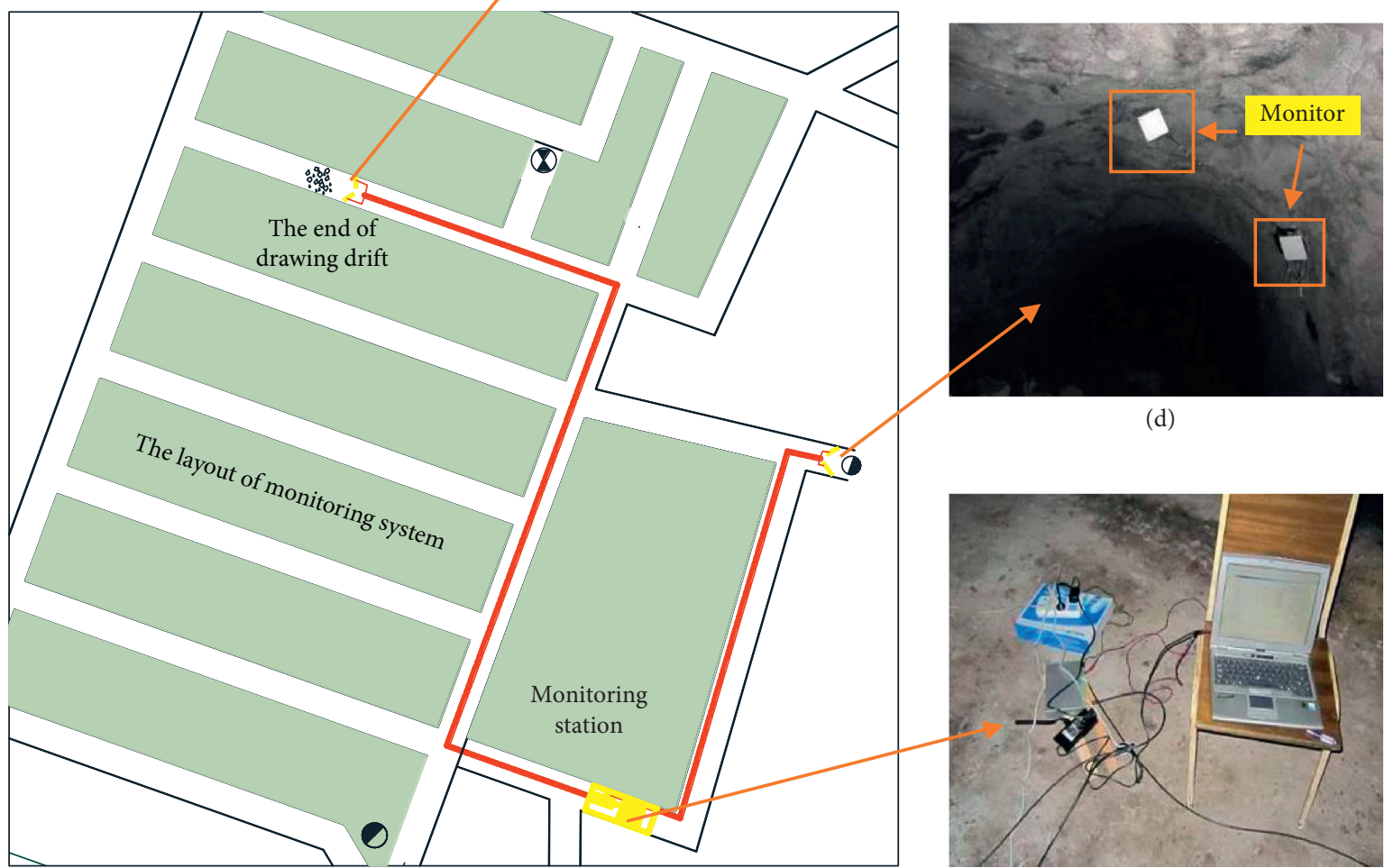

(f)

FIgURE 6: The layout of monitoring system: (a) monitors on the roof of the drift near drawing point; (b) monitors; (c) video on the roof of the drift near drawing point; (d) monitors next to the ore pass; (e) monitoring station.

uncovered areas appeared among mined orebodies. These areas could not be drawn, which was the loss of ores.

Through the above two forms of ellipsoid arrangement models, there was some irrationality existing in the determination of stope structure parameters by this method. Based on the ellipsoid arrangement theory, the IEZ and mined orebody were arranged in the stope, which had the same quality of drawing. The dilution and loss rate of the two forms of mined orebody arrangement were calculated. The results showed that the repeated coverage rate was $6.38 \%$ and the noncoverage rate was $10.43 \%$. Repeated coverage means that the ores in this area will be mined twice, resulting in the fact that the waste rock could inevitably be mixed in the drawing process, which would further reduce the recovery rate. Noncoverage means that the ores in this area have not been drawn, resulting in the loss of ores and lower recovery rates.

\section{Optimization of Stope Structure Parameters}

In the caving process of SLC, the mixed waste rock came from both sides and top of drawing points. The parameters affecting ore loss and dilution indexes mainly include sublevel height and drift spacing. Meanwhile, ore loss and dilution are not affected by the single parameters, but by joint effect. The height and width of mined orebodies corresponding to different qualities of drawing ores are shown in Table 2. These data could be used to analyze the relationship between the height and width of the mined orebody and then determine the reasonable stope structural parameters. Through comparison calculation of the height and width of the mined orebodies in stope structure, the heightwidth ratios $(\mathrm{H} / \mathrm{W})$ were $1.96 \sim 2.36$. According to the $\mathrm{H} / \mathrm{W}$ of the mined orebodies, the reasonable stope structural parameters proportion ratios of $\mathrm{H}$ and $\mathrm{S}$ could be concluded 


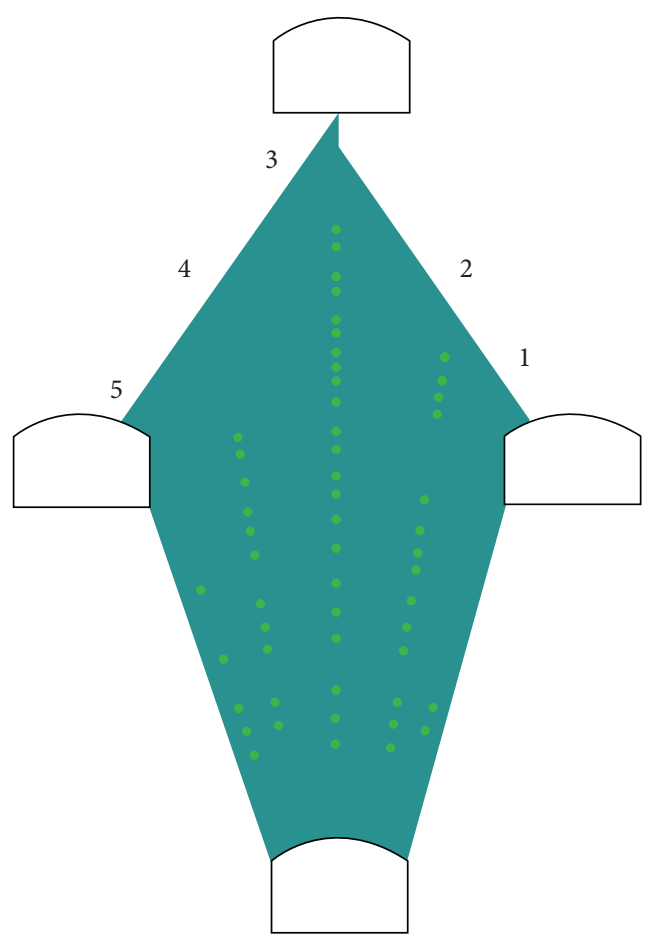

Figure 7: The location of monitored markers in the test.

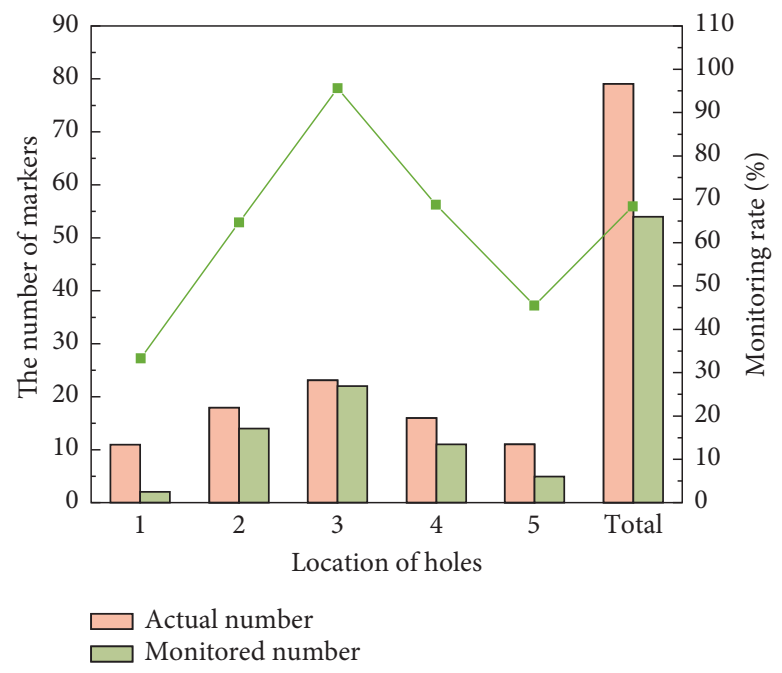

FIgURE 8: The location of monitored markers in the test.

as $0.98 \sim 1.18$. Presently, the values $H$ and $S$ were 18 and $20 \mathrm{~m}$, which were applied in the Meishan iron mine. These parameters were inconsistent with the proportion of mined orebodies, which led to a poor recovery index. The matching degree between stope structural parameters and flow behavior of ore and rock was low, which led to the dilution increased in the middle and late periods of drawing. Therefore, it was necessary to improve the matching degree between structural parameters and the flow behavior of ores.

According to the results of the mined orebody in situ measurement test, several schemes of stope structural parameters were designed based on the specific situation, which is shown in Table 3. The more reasonable parameters were selected based on the matching degree between the mined orebody's shape and the stope structure. According to different structural parameters, let the mined orebodies be tangential to the outline of a blasted slice. The mined orebody's shape was matched with different stope structural parameters $(H \times S=18 m \times 20 \mathrm{~m}, \quad 20 \mathrm{~m} \times 18 \mathrm{~m}, \quad 20 \mathrm{~m} \times 20 \mathrm{~m}$, $22 m \times 20 \mathrm{~m}, 24 m \times 20 \mathrm{~m}$, and $24 m \times 22 \mathrm{~m}$, resp.), and the corresponding coverage rate was calculated.

The matching degree between the mined orebody's shape and structural parameter schemes is shown in Figures 14(a)14(f). Compared with the other five schemes, the mined orebody's shape that was obtained through the current 


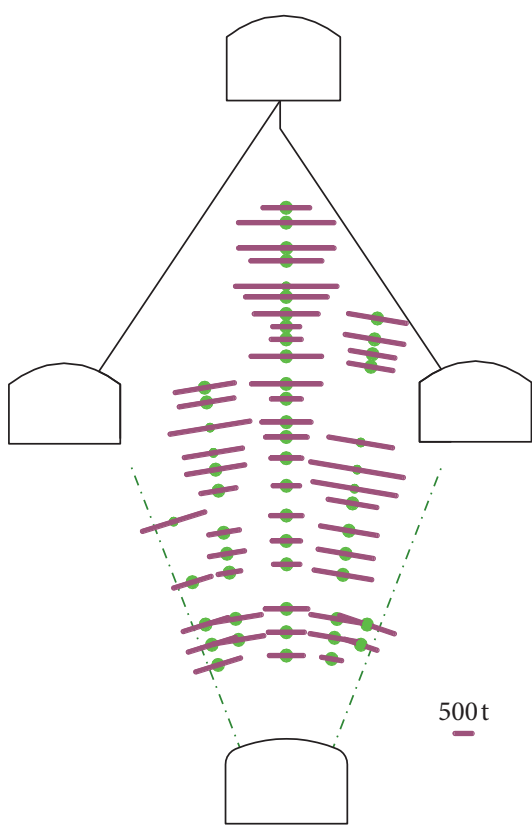

(a)

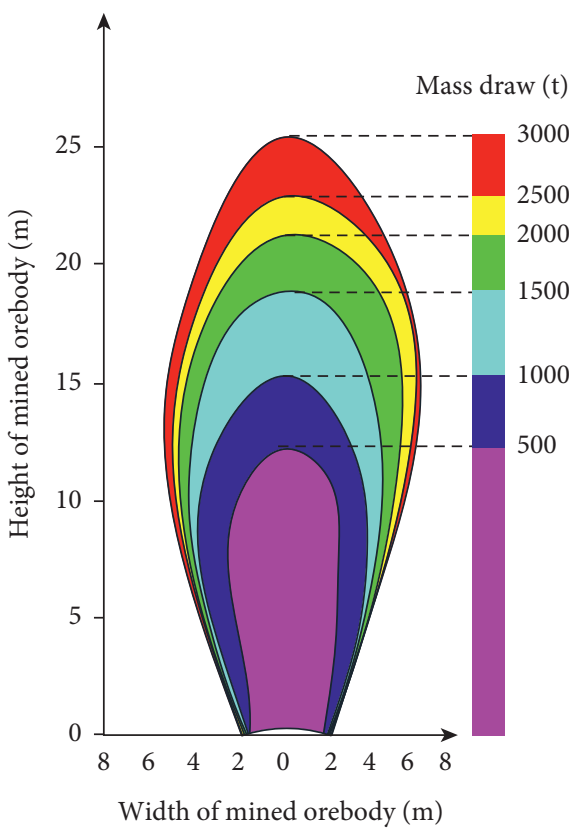

(b)

FIGURE 9: (a) Markers monitored in the test and their corresponding quality of drawing ore. (b) Mined orebodies were depicted by the data from the markers.

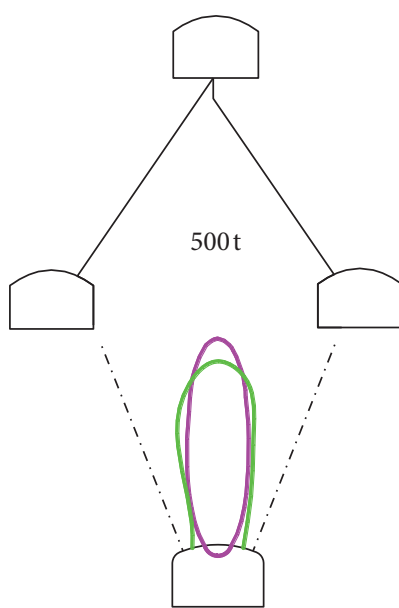

(a)

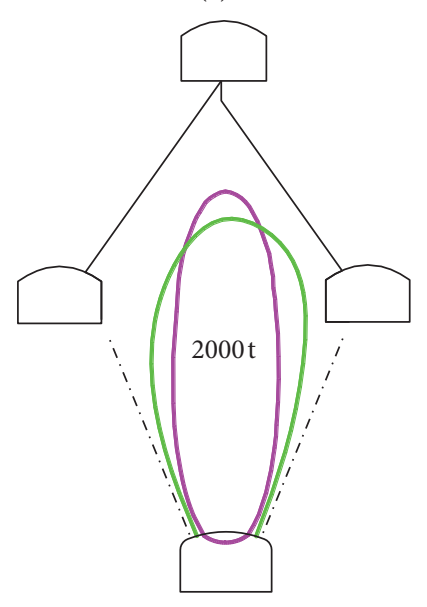

(d)

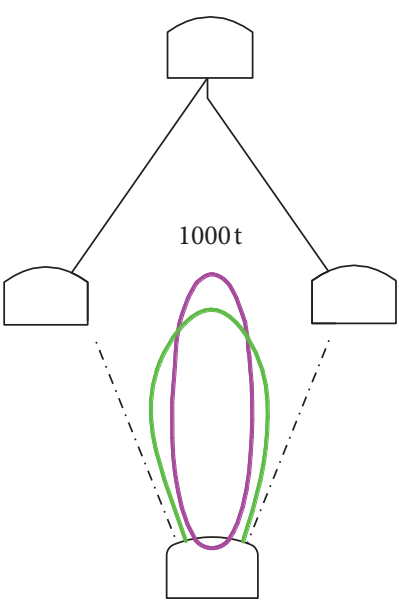

(b)

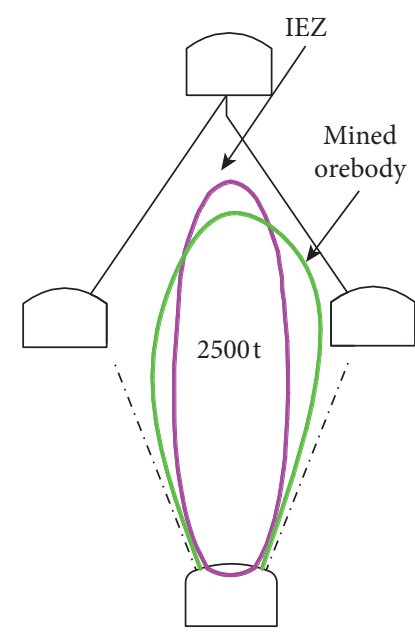

(e)

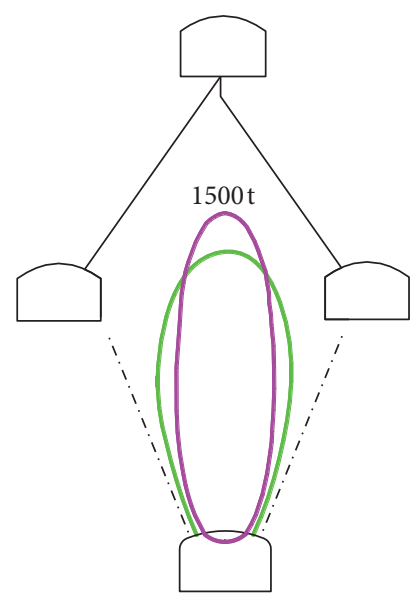

(c)

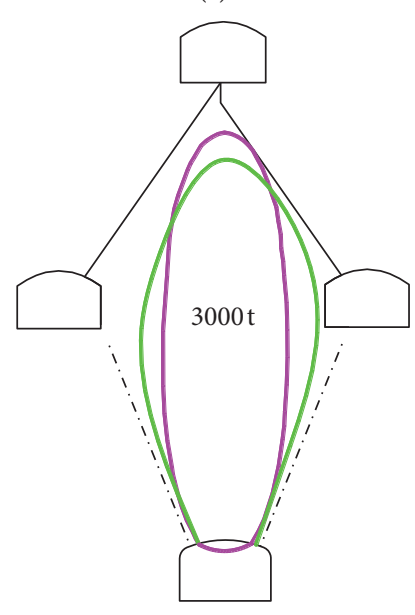

(f)

FIGURE 10: Comparison of the mined orebody's shape and the IEZ's shape in the test. 
TABLE 1: Data of the height and width of the mined orebody.

\begin{tabular}{lcc}
\hline Number & $Z(\mathrm{~m})$ & $Y(\mathrm{~m})$ \\
\hline 1 & 11.5 & 5 \\
2 & 14.5 & 6.8 \\
3 & 17.7 & 8.6 \\
4 & 20.2 & 10.2 \\
5 & 23.2 & 10.7 \\
6 & 25.4 & 11.5 \\
\hline
\end{tabular}

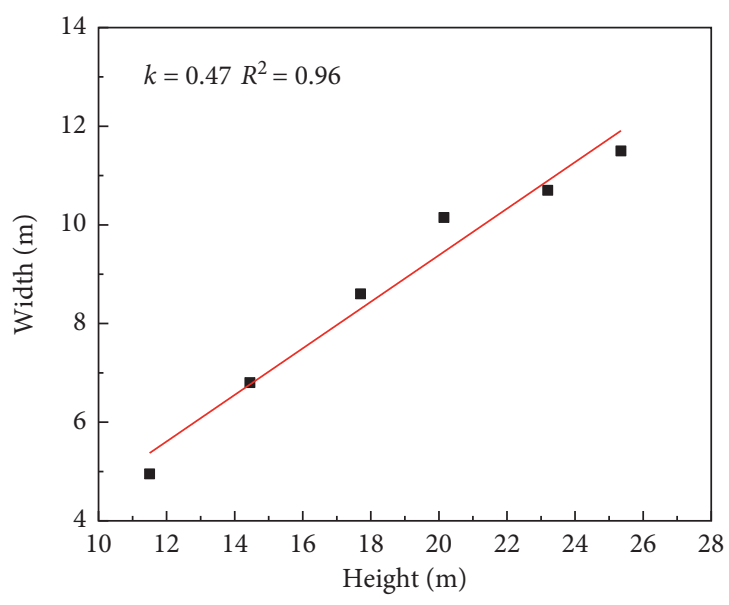

Figure 11: The linear relation between height and width of the mined orebody.

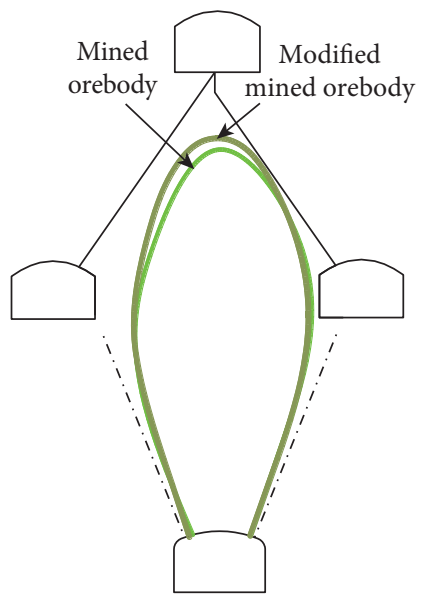

FIGURE 12: The modified mined orebody.

structural parameters scheme $(H \times S=18 m \times 20 \mathrm{~m})$ had a relatively low coverage rate.

The value of coverage rate and uncovered rate of each scheme is listed in Figure 15. The coverage rate could determine the matching degree between each scheme and the mined orebody. The matching degree of scheme 4 was the highest, followed by schemes 2, 5, and 6. The matching degree was higher, and the proportional relationship between stope structural parameters and the mined orebody's shape was closer. The H/S value of scheme 4 was 1.1 , which coincided with the reasonable ratio range (0.98 1.18). Here, the structural parameter was $22 \mathrm{~m} \times 20 \mathrm{~m}$. The area of the blasted slice increased from 337 to $417 \mathrm{~m}^{2}$, which was improved by $23.74 \%$. With the improvement of the drawn index, mining efficiency could be significantly increased.

Verification tests were employed on the optimized stope structural parameters in the Meishan iron mine. Alternatively, the mine had introduced a series of advanced drilling equipment and charging trolleys since mining with large structural parameters, which could fully meet the mining requirements of sublevel height $(H=22 \mathrm{~m})$. Alternatively, the ore body was still thick and had the conditions to further increase the sublevel height under the current mining level of $-306 \mathrm{~m}$. Hence, in situ tests with increasing the sublevel height were conducted. The sublevel height was increased from 18 to $22 \mathrm{~m}$ as the drift spacing was $20 \mathrm{~m}$. The blasted slice was determined by the optimized structural parameters as displayed in Figure 16.

The specific parameters were $H=22 \mathrm{~m}, L=20 \mathrm{~m}$, $B=2.4 \mathrm{~m}$, and $W=6 \mathrm{~m}$. The in situ tests were selected at the S4 drift of $-306 \mathrm{~m}$ level, and the plane position of the test stope is shown in Figure 17(a). The blast holes were drilled with the Simba H1354 drilling trolley in a double drilling center mode. The height of the drilling center was $1.9 \mathrm{~m}$, the interval was $1.2 \mathrm{~m}$, and the diameter of the blast hole was $91 \mathrm{~mm}$. The detailed arrangement of blast holes is shown in Figure 17(b).

The geological ore capacity of the test stope was $45,767 \mathrm{t}$, and the average geological grade was $46.6 \%$. The drawing results are shown in Table 4. According to the calculation formulas of ore loss and dilution (1)-(3), the recovery rate of the new test stope and the dilution rate could be calculated as $90.64 \%$ and $9.95 \%$.

$$
\begin{array}{r}
\text { Waste rock - mixing rate : } Y=\frac{C-C_{c}}{C-C_{y}} \times 100, \\
\text { ore recovery rate: } H_{k}=\frac{Q_{c}}{Q}(100-Y), \\
\text { ore dilution rate : } P=\frac{C-C_{c}}{C} \times 100 .
\end{array}
$$

In the formulas, $Q$ was industrial reserves of ore bodies $(\mathrm{t}), Q_{\mathrm{c}}$ was the quality of mined ores $(\mathrm{t}), C$ was in situ grade of industrial reserves of ore $(\%), C_{c}$ was the grade of recovered mined ore and waste rock (\%), and $C_{y}$ was the grade of mixed waste rock (\%). In addition, $C_{y}$ was a constant; the value was $15 \%$.

The test results indicated that the new sublevel height was beneficial to improve the stability of mining and 


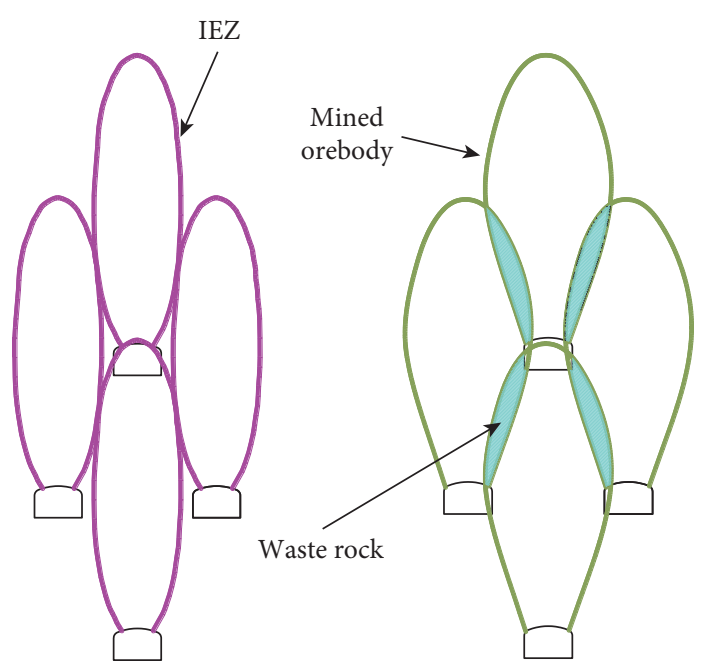

(a)
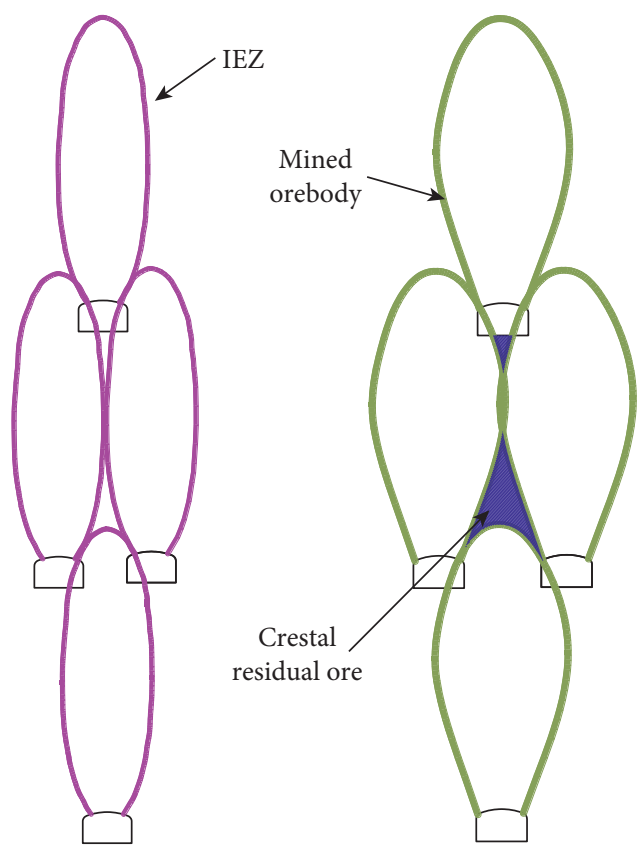

(b)

FIgURE 13: The mined orebody and IEZ specific arrangement. (a) Arrangement of IEZs and mined orebodies with large spacing. (b) Arrangement of IEZs and mined orebodies with high sublevel.

TABLE 2: Height and width of mined orebody in the test.

\begin{tabular}{lccr}
\hline Drawing ores $(\mathrm{t})$ & Height $(\mathrm{m})$ & Width $(\mathrm{m})$ & \\
\hline 500 & 11.8 & 5 & 2.36 \\
1000 & 14.9 & 7.6 & 1.96 \\
1500 & 18.5 & 8.7 & 2.12 \\
2000 & 20.9 & 10 & 2.09 \\
2500 & 22.5 & 10.8 & 2.08 \\
3000 & 25 & 11.5 & 2.17 \\
\hline
\end{tabular}

TABLE 3: Stope structure parameter scheme.

\begin{tabular}{lcc}
\hline Scheme & Height $(\mathrm{m})$ & Drift spacing $(\mathrm{m})$ \\
\hline 1 & 18 & 20 \\
2 & 20 & 18 \\
3 & 20 & 20 \\
4 & 22 & 20 \\
5 & 24 & 20 \\
6 & 24 & 22 \\
\hline
\end{tabular}

preparatory work as well as production efficiency. The excellent drawing indexes were obtained under the new stope structural parameters, proving that the stope structural parameters determined by the mined orebody's shape were a reasonable matching relationship. It was helpful to improve the economic benefit of the mine. 


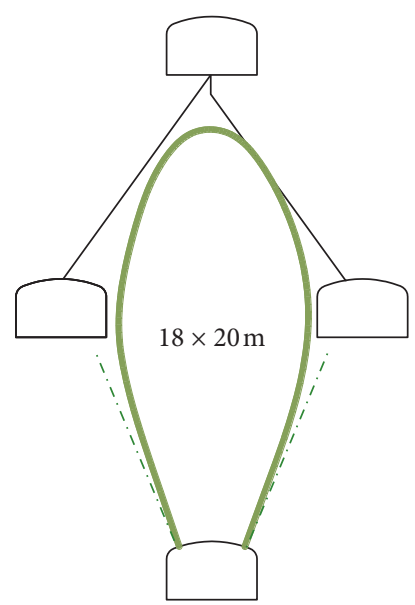

(a)

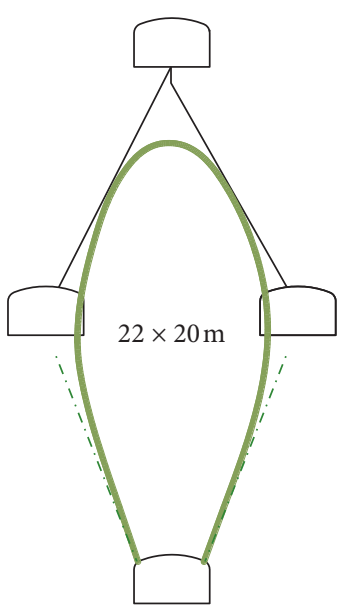

(d)

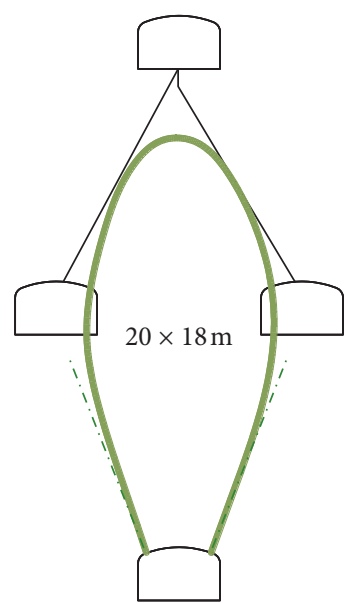

(b)

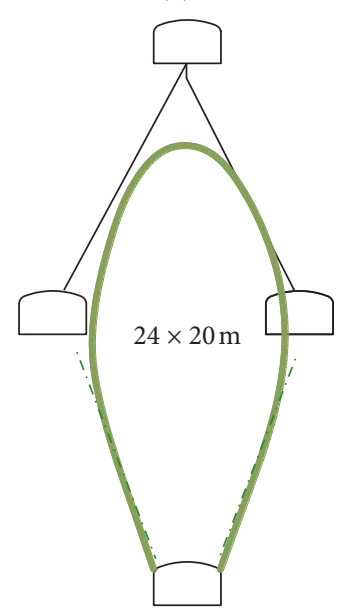

(e)

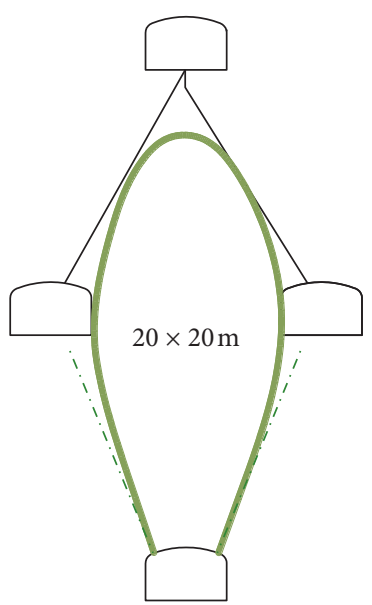

(c)

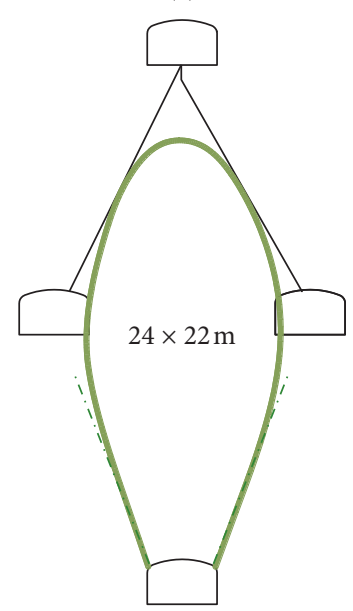

(f)

FIGURE 14: The matching degree between the mined orebody's shape and structural parameter schemes.

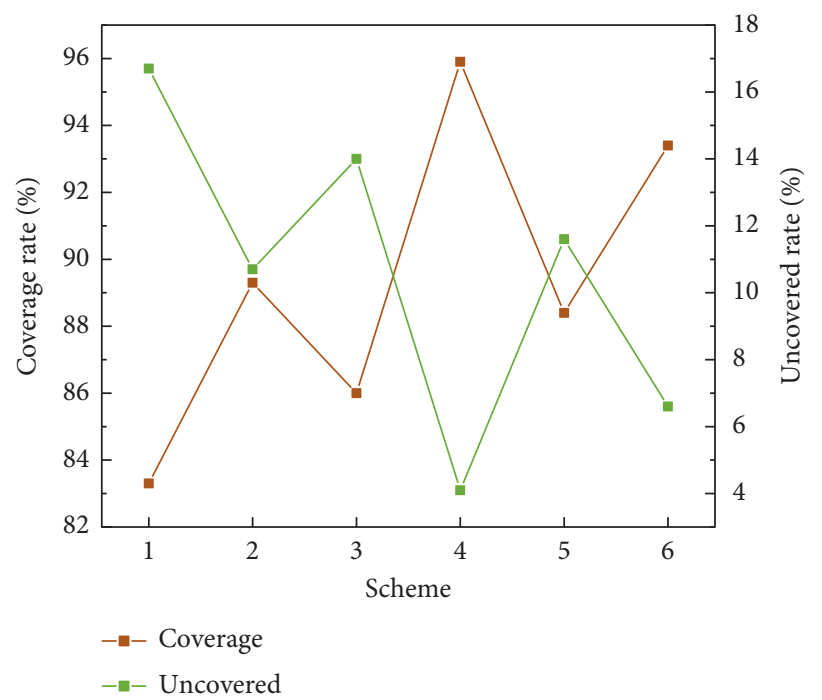

FIGURE 15: Coverage and uncovered rate of mined orebody of each structural parameter scheme. 


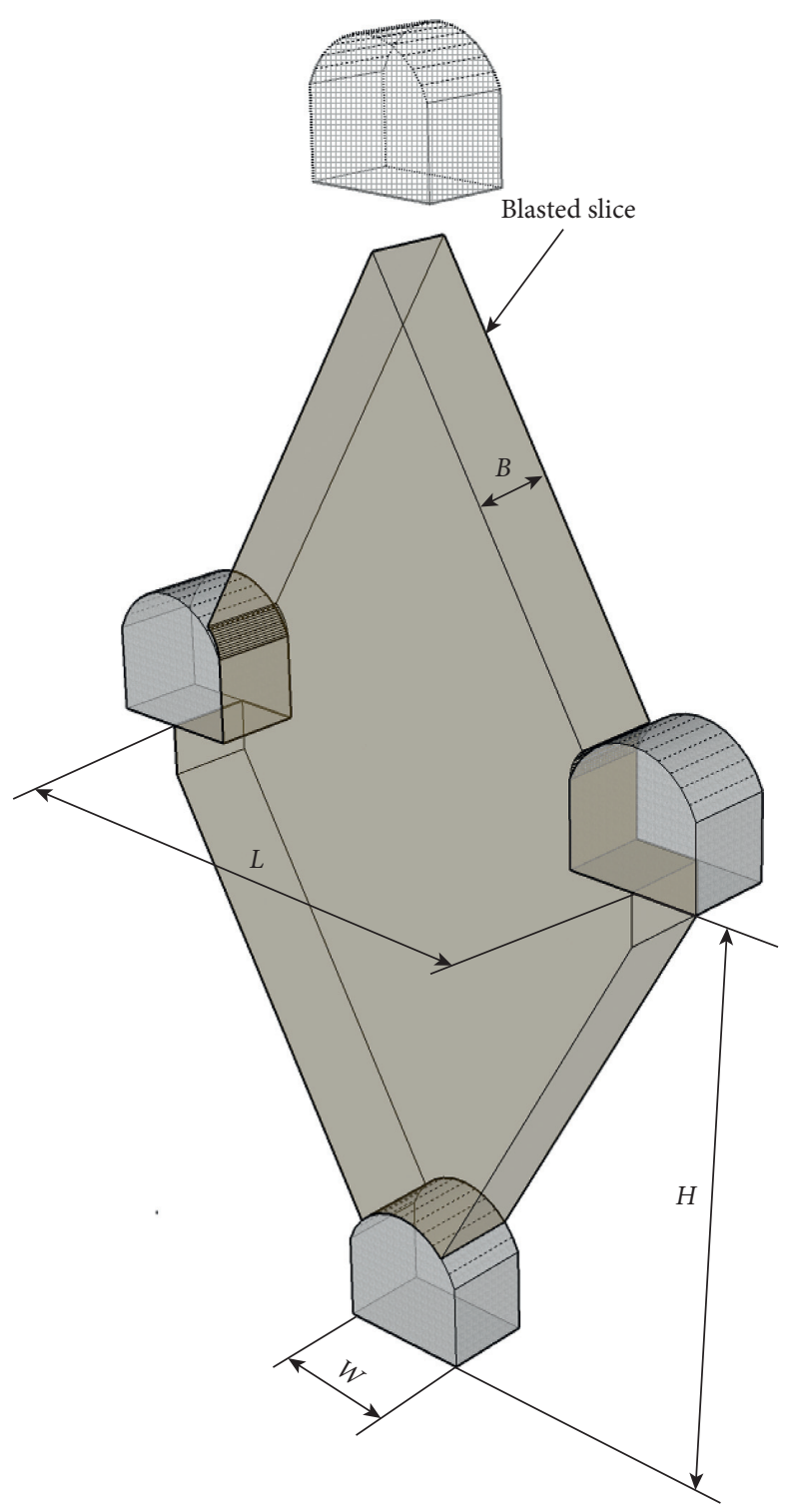

FIGURE 16: The blasted slice determined by the optimized structural parameters.

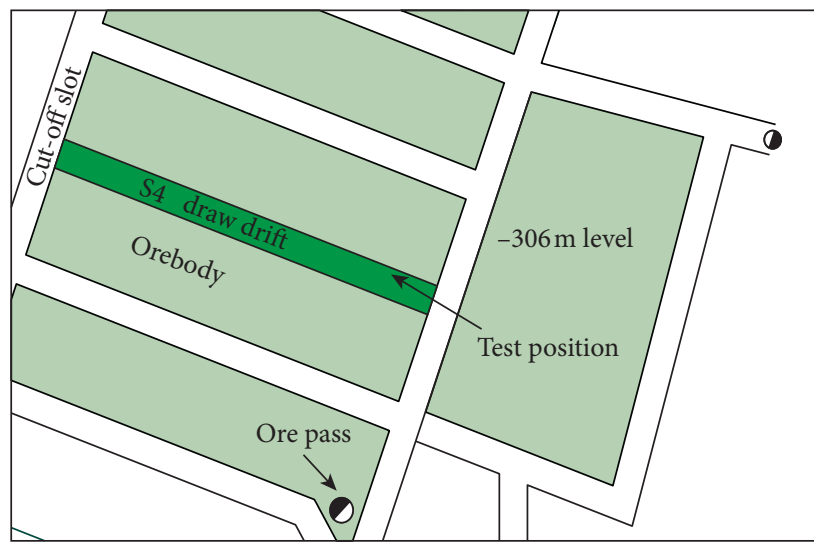

(a)

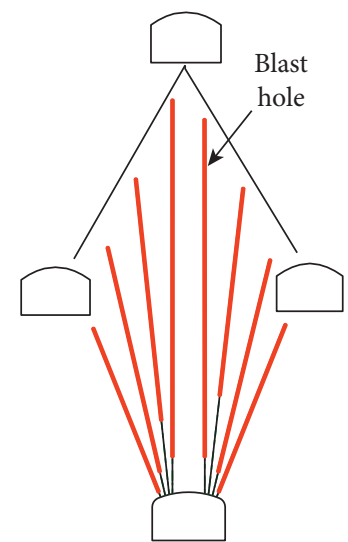

(b)

Figure 17: (a) The plane position of the test stope. (b) The detailed arrangement of blast holes in verification tests. 
TABLE 4: The drawing ore date in the test stope.

\begin{tabular}{lllll}
\hline Number & $Q(\mathrm{t})$ & $C(\%)$ & $Q_{c}(\mathrm{t})$ & \\
\hline 1 & 3258 & 45.64 & 3326 & \\
2 & 3289 & 45.72 & 3196 & 42.1 \\
3 & 3313 & 45.29 & 3294 & 42.1 \\
4 & 3303 & 46.22 & 3603 & 42.1 \\
5 & 3326 & 46.88 & 3104 & 42.1 \\
6 & 3347 & 46.35 & 3493 & 42.9 \\
7 & 3366 & 46.96 & 3679 & 42.9 \\
8 & 3355 & 46.64 & 3556 & 42.9 \\
9 & 3372 & 47.17 & 3667 \\
10 & 3354 & 47.38 & 3594 & 41.39 \\
11 & 3339 & 47.37 & 3730 & 41.39 \\
13 & 3328 & 47.15 & 3973 \\
\hline
\end{tabular}

\section{Conclusions}

Here, based on the Meishan iron mine with sublevel caving (SLC) method, the mined orebody's shape measurement method and the relationship between mined orebody and IEZ were studied. Meanwhile, the structure parameters of the stope were optimized using the mined orebody's shape. In the field test, the markers were arranged in a single blasted slice, the mined orebody was measured by in situ test method. The monitored recovery rate of markers was $68.4 \%$. The mined orebody's shape was compared with IEZ's shape, and the difference increased with increasing height. The reasonable stope structure parameters were finally optimized through the mined orebody's matched with designed stope structures. The sublevel height $(H)$ was $22 \mathrm{~m}$, and the drift spacing $(S)$ was $20 \mathrm{~m}$. Besides, the verification tests were employed on the optimized stope structural parameters, the recovery rate of the new test stope was $90.64 \%$, and the dilution rate was $9.95 \%$, indicating that the new structural parameters were beneficial to improve production efficiency.

\section{Data Availability}

The data used to support the findings of the study are available from the corresponding author upon request.

\section{Conflicts of Interest}

The authors declare that they have no conflicts of interest.

\section{Acknowledgments}

The study was supported by grants from the National Natural Science Foundation of China (nos. 51534003 and 51404065), the Basic Scientific Research Program funded for Central Universities and Colleges of China (no. 140104008), and the National Key Research and Development Program of China (no. 2016YFC0801601). The authors are grateful for their support.

\section{References}

[1] I. D. Brunton, S. J. Fraser, J. H. Hodgkinson, and P. C. Stewart, "Parameters influencing full scale sublevel caving material recovery at the Ridgeway gold mine," International Journal of Rock Mechanics and Mining Sciences, vol. 47, no. 4, pp. 647-656, 2010.

[2] L. Wang, A. Shao, X. Liu, L. Yang, and H. Ding, "New computational framework for modeling the gravity flow behavior of sublevel caving material," Computers and Geotechnics, vol. 125, Article ID 103675, 2020.

[3] D. S. S. Sandanayake, E. Topal, and M. W. A. Asad, "Designing an optimal stope layout for underground mining based on a heuristic algorithm," International Journal of Mining Science and Technology, vol. 25, no. 5, pp. 767-772, 2015.

[4] K. Yu, F. Ren, G. Chitombo, R. Puscasu, and L. Kang, "Optimum sublevel height and drift spacing in sublevel cave mining based on random medium theory," Mining, Metallurgy \& Exploration, vol. 37, no. 2, pp. 681-690, 2020.

[5] R. He and F. Ren, "Stop structure parameters optimization of deep ore body in beiminghe iron mine," Metal Mine, vol. 432, no. 6, pp. 16-18, 2012.

[6] G. Tao, Z. Liu, F. Ren, and Q. Ren, "Optimization research of stope structural parameters in sublevel caving with non-pillar," China Coal Society, vol. 35, no. 8, pp. 1269-1272, 2010.

[7] A. Jin, H. Sun, S. Wu, and Y. Gao, "Confirmation of the upside-down drop shape theory in gravity flow and development of a new empirical equation to calculate the shape," International Journal of Rock Mechanics and Mining Sciences, vol. 92, pp. 91-98, 2017.

[8] F. Ren, Stochastic Medium Theory for Draw and its Application, Metallurgical Industry Press, Beijing, China, 1994.

[9] G. Tao, M. Lu, X. Zhang, R. Zhang, and Z. Zhu, "A new diversion drawing technique for controlling ore loss and dilution during longitudinal sublevel caving," International Journal of Rock Mechanics and Mining Sciences, vol. 113, pp. 163-171, 2019.

[10] G. Tao, S. Yang, and F. Ren, "Experimental research on granular flow characters of caved ore and rock," Rock and Soil Mechanics, vol. 30, no. 10, pp. 2950-2954, 2009.

[11] M. E. Kuchta, "A revised form of the Bergmark-Roos equation for describing the gravity flow of broken rock," Mineral Resources Engineering, vol. 11, no. 4, pp. 349-360, 2002.

[12] Qi Wang, Z. Jiang, B. Jiang, H. Gao, Y. Huang, and P. Zhang, "Research on an automatic roadway formation method in deep mining areas by roof cutting with high-strength bolt- 
grouting," International Journal of Rock Mechanics and Mining Sciences, vol. 128, Article ID 104264, 2020.

[13] Y. Wang, W. K. Feng, R. L. Hu, and C. H. Li, "Fracture evolution and energy characteristics during marble failure under triaxial fatigue cyclic and confining pressure unloading (FC-CPU) conditions," Rock Mechanics and Rock Engineering, vol. 54, pp. 799-818, 2021.

[14] Q. Wang, Y. Wang, M. C. He et al., "Experimental research and application of automatically formed roadway without advance tunneling," Tunnelling and Underground Space Technology, vol. 114, no. 3, Article ID 103999, 2021.

[15] A. Li, F. Dai, Y. Liu, H. B. Du, and R. C. Jiang, "Dynamic stability evaluation of underground cavern sidewalls against flexural toppling considering excavation-induced damage," Tunnelling and Underground Space Technology, vol. 112, Article ID 103903, 2021.

[16] R. Kvapil, Underground Mining Methods Handbook, Society of Mining, Metallurgy and Explorations, Englewood, CO, USA, 1982.

[17] I. Janelid and R. Kvapil, "Sublevel caving," International Journal of Rock Mechanics and Mining Science \& Geomechanics Abstracts, vol. 3, no. 2, pp. 129-132, 1966.

[18] R. Kvapil, "Underground Mining Methods Handbook," The Mechanic Sand Design of Sublevel Caving Systems, US Department of Energy, New York, NY, USA, 1982.

[19] Mattson, Stewart, and J. A. Cox, "Sublevel caving and draw control procedures at Granduc," Mineral Metallaurgy Bulletin, vol. 66, no. 732, pp. 45-56, 1973.

[20] D. O'Sullivan and A. Newman, "Optimization-based heuristics for underground mine scheduling," European Journal of Operational Research, vol. 241, no. 1, pp. 248-259, 2015.

[21] P. O. Sandstrom, "Application and optimization of sublevel caving techniques," Engineering and Mining Journal, vol. 6, pp. 112-125, 1972.

[22] F. Melo, F. Vivanco, C. Fuentes, and V. Apablaza, "On drawbody shapes: from Bergmark-Roos to kinematic models," International Journal of Rock Mechanics and Mining Sciences, vol. 44, no. 1, pp. 77-86, 2007.

[23] Q. X. Meng, W. Y. Xu, H. L. Wang, X. Y. Zhuang, W. C. Xie, and T. Rabczuk, "DigiSim-an open source software package for heterogeneous material modeling based on digital image processing," Advances in Engineering Software, vol. 148, Article ID 102836, 2020.

[24] C. Zhu, M. C. He, M. Karakus, X. H. Zhang, and Z. Guo, “The collision experiment between rolling stones of different shapes and protective cushion in open-pit mines," Journal of Mountain Science, vol. 18, no. 5, pp. 1391-1403, 2021.

[25] Q. Yin, J. Y. Wu, C. Zhu, M. C. He, and Q. X. Meng, "Shear mechanical responses of sandstone exposed to high temperature under constant normal stiffness boundary conditions," Geomechanics and Geophysics for Geo-Energy and GeoResources, vol. 7, no. 35, 2021.

[26] R. Castro, R. Trueman, and A. Halim, "A study of isolated draw zones in block caving mines by means of a large 3D physical model," International Journal of Rock Mechanics and Mining Sciences, vol. 44, no. 6, pp. 860-870, 2007.

[27] R. Castro and M. Pineda, "The role of gravity flow in the design and planning of large sublevel stopes," Journal of the South African Institute of Mining and Metallurgy, vol. 115, no. 2, pp. 113-118, 2015.

[28] Z. Zhang and M. Wimmer, "A case study of dividing a single blast into two parts in sublevel caving," International Journal of Rock Mechanics and Mining Sciences, vol. 104, pp. 84-93, 2018.
[29] A. Gustafson, H. Schunnesson, J. Paraszczak, G. Shekhar, and P. Brnnman, "Operator influence on the loading process at LKAB's iron ore mines," Journal of the South African Institute of Mining and Metallurgy, vol. 120, no. 3, pp. 191-202, 2020.

[30] J. Cao, F. Ren, J. Zhang, and Q. Yang, "Experimental study on diversion drawing by stress-relieve sublevel caving method," Journal of Northeastern University, vol. 32, pp. 1186-1189, 2011.

[31] J. Wu, W. Lin, and H. Hu, "Post-failure simulations of a large slope failure using 3DEC: the Hsien-du-Shan slope," Engineering Geology, vol. 242, pp. 92-107, 2018.

[32] R. Xia, B. Li, X. Wang, T. Li, and Z. Yang, "Measurement and calibration of the discrete element parameters of wet bulk coal," Measurement, vol. 142, pp. 84-95, 2019.

[33] R. Castro, F. Gonzalez, and E. Arancibia, "Development of a gravity flow numerical model for the evaluation of drawpoint spacing for block/panel caving," Southern African Institute of Mining and Metallurgy, vol. 109, no. 7, pp. 393-400, 2009.

[34] D. Qiao, Research on particle movement rule and draw theory, PhD thesis, Northeastern University, Boston, MA, USA, 2003.

[35] Y. Hu, F. Ren, H. Ding, Y. Fu, and B. Tan, "Study on the process and mechanism of slope failure induced by mining under open pit slope: a case study from Yanqianshan iron mine, China," Advances in Civil Engineering, vol. 2019, Article ID 6862936, 26 pages, 2019.

[36] H. Ding, S. Chen, S. Chang, G. Li, and L. Zhou, "Prediction of surface subsidence extension due to underground caving: acase study of Hemushan iron mine in China," Mathematical Problems in Engineering, vol. 2020, Article ID 5086049, 10 pages, 2020.

[37] B. Tan, Z. Zhang, R. He, and Q. Zhu, "Discussion on the rationality and experimental research of the ore-drawing ellipsoid arrangement theory," Journal of Northeastern University, vol. 40, no. 7, pp. 1014-1019, 2019. 